\title{
Contextos da política de águas e novas abordagens pela perspectiva das reformas administrativas no Brasil
}

\author{
da Trindade Junior, Adilson Pio \\ Contextos da política de águas e novas abordagens pela perspectiva das reformas administrativas no Brasil \\ Administração Pública e Gestão Social, vol. 13, núm. 1, 2021 \\ Universidade Federal de Viçosa, Brasil \\ Disponible en: http://www.redalyc. org/articulo.oa?id=351564966010
}

\section{(c) $(1) \Theta$}

Esta obra está bajo una Licencia Creative Commons Atribución-NoComercial-SinDerivar 3.0 Internacional. 


\section{Contextos da política de águas e novas abordagens pela perspectiva das reformas administrativas no Brasil}

Contexts of the water policy and new approaches by the perspective of administrative reforms in Brazil
Contextos de la política de aguas y nuevos enfoques por la perspectiva de reformas administrativas en Brasil.

Adilson Pio da Trindade Junior

Pesquisador Membro, na Rede WATERLAT-GOBACIT,

Redalyc: http://www.redalyc.org/articulo.oa?

Brasil

trindadejr@alumni.usp.br

id $=351564966010$

Recepción: 28 Septiembre 2018

Aprobación: 16 Abril 2020

Publicación: 01 Enero 2021

\section{Resumo:}

Objetivo da pesquisa: Apresentar a construção de um argumento ao explorar, por meio de leitura contextualizada da Política Nacional de Recursos Hídricos (PNRH), como as reformas, que buscaram o modelo gerencial na administração pública brasileira, estabeleceram variáveis e condicionantes à política participativa e descentralizada.

Enquadramento teórico: $\mathrm{O}$ embasamento teórico será, predominantemente, interdisciplinar, porque envolve a análise de um tema complexo relacionado a um bem de domínio público. Serão articuladas teorias das áreas das Ciências Ambientais, da Administração Pública e da Ciência Política.

Metodologia: A pesquisa de natureza qualitativa valeu-se de revisão bibliográfica exploratória e descritiva, assim como foi realizada a análise de documentos, tais como planos e programas. Além disso, foram realizadas entrevistas semiestruturadas com atores do sistema.

Resultados: Como resultado, proporcionou uma discussão sobre a PNRH e seus fundamentos, especialmente os de descentralização e de participação, e sobre como as características da implementação dessa política estabeleceram condições muito específicas ao funcionamento do sistema brasileiro de gestão das águas. Desse modo, o artigo propõe chaves analíticas características da administração pública e da ciência política, a saber: modelos de análise combinada de políticas públicas e arranjos institucionais e burocracias para a renovação do debate sobre a água no Brasil.

Originalidade: Neste artigo, analisa-se de forma retrospectiva uma política pública ambiental, além de explorar basicamente a problemática de implementação, sobretudo, pela lente teórica da administração pública. Assim, a maior contribuição reside na articulação de diferentes áreas. Trata-se de um esforço interdisciplinar que busca outras respostas aos problemas relacionados à efetividade, os quais foram observados na literatura sobre a PNRH.

Contribuições teóricas e práticas: A abordagem desenvolvida buscou oferecer novas opções de análise ao propor chaves analíticas de áreas transversais às ciências ambientais. Em outra perspectiva, a aplicada, partiu-se das mesmas chaves teóricas; porém, agora, percebendo-as como ferramentas que podem ser manipuladas no sentido de aprimoramento do processo de implementação da PNRH.

Palavras-chaVe: Recursos naturais, Políticas Públicas, Reformas.

\section{Abstract:}

Research objective: To present the building of an argument by exploring the way the managerial reforms regarding water resources, which sought a New Managerialism-centered approach to Brazilian public administration, established variables and conditions to decentralized and participatory policy. To do so through a contextualized reading of Brazil's National Water Resources Policy ("Política Nacional de Recursos Hídricos", referred henceforth as PNRH).

Theoretical framework: The theoretical foundation of this project will be primarily interdisciplinary, as it involves analyzing complex themes and their relations to public assets. There will be a combination of environmental science, public administration, and political science theories.

Methodology: This qualitative research made use of exploratory and descriptive review of relevant bibliography, as well as the analyses of documents such as plans and programs. Additionally, semi-structured interviews with agents of the system were carried out. 
Results: The research allowed me to open a debate about the PNRH and its foundations, especially where decentralization and participation is concerned; it also allowed me to discuss the way the implementation of this policy set down very specific conditions to the operation of the Brazilian water management system. In accordance with these results, I propose the adoption of some key methods of investigation, typical of public administration and political science studies, e.g. models of combined analysis of government policies, institutional arrangements and bureaucracy as they relate to the renovation of public debate about water in Brazil.

Originality: Within this paper, I carry out a retrospective examination of an example of environmental public policy; I also explore problems of implementation in a basic sense, especially through the lens of public administration. Therefore, the greatest contribution of this paper resides in the combination of different areas of knowledge. It is an interdisciplinary effort that searches for alternative answers to questions about efficacy, as observed in the literature about the PNRH.

Theoretical and practical contributions: The approach I developed sought to offer new options of analysis, by proposing the adoption of key methods of investigation belonging to areas of knowledge that are transversal to environmental science. Within the applied perspective, I could, while keeping the same theoretical foundations, understand these methods of investigation as tools for the improvement of the implementation process of the PNRH.

KeYworDs: Natural Resource, Public Policy, Reforms.

\section{Resumen:}

Objetivo de la investigación: Presentar la construcción de un argumento al explorar, a través de la lectura contextualizada de la Política Nacional de Recursos Hídricos (PNRH), cómo las reformas, que buscaron el modelo de gestión en la administración pública brasileña, establecieron variables y condiciones para la política participativa y descentralizada.

Marco teórico: El marco teórico será predominantemente interdisciplinario, porque involucra el análisis de un tema complejo relacionado con un bien de dominio público. Se articularán teorías en las áreas de Ciencias Ambientales, Administración Pública y Ciencias Políticas.

Metodología: La investigación es de naturaleza cualitativa, por lo que se echó mano a una revisión bibliográfica, de carácter explorador y descriptivo, así como al análisis de documentos, como planes y programas. Además, se realizaron entrevistas semiestructuradas con actores del sistema.

Resultados: Como resultado, brindó una discusión sobre el PNRH y sus fundamentos, especialmente los de descentralización y participación; y cómo las características de la implementación de esta política establecieron condiciones muy específicas para el funcionamiento del sistema brasileño de gestión del agua. Así, el artículo propone claves analíticas propias de la administración pública y la ciencia política, a saber: modelos de análisis combinado de políticas públicas y arreglos institucionales y burocracias para la renovación del debate sobre el agua en Brasil.

Originalidad: En este artículo se analiza retrospectivamente una política pública ambiental, además de explorar básicamente el problema de implementación, sobre todo, a través del lente teórico de la administración pública. Así, la mayor contribución radica en la articulación de diferentes áreas. Se trata de un esfuerzo interdisciplinario que busca otras respuestas a los problemas relacionados con la efectividad, que se han observado en la literatura sobre la PNRH.

Contribuciones teóricas y prácticas: El enfoque desarrollado buscó ofrecer nuevas opciones de análisis proponiendo claves analíticas de áreas transversales a las ciencias ambientales. En otras perspectivas, el abordaje aplicado, partió de las mismas claves teóricas; sin embargo, ahora las percibe como herramientas que se pueden manipular para mejorar el proceso de implementación del PNRH.

Palabras ClaVe: Recursos naturales, Políticas públicas, Reformas.

\section{INTRODUÇÃO}

A Política Nacional de Recursos Hídricos (PNRH) do Brasil constitui uma legislação inovadora e com princípios altamente democráticos (Jacobi, 2004). Isso se dá por estabelecer "um novo paradigma, da gestão integrada, descentralizada e participativa dos recursos hídricos em todos os níveis territoriais da administração" (ANA, 2002, p.7). Entretanto, ao realizar uma primeira aproximação e (ou) contextualização com a problemática geral do presente paper, verifica-se que todo ambiente institucional/organizacional da PNRH compreende um subconjunto complexo e segmentado, o qual se desenvolve na ambiência da administração pública e suas burocracias especializadas.

Dessa maneira, um dado histórico fundamental a respeito da PNRH é que esta foi instituída em 1997, na sequência da reforma gerencial de 1995, fato este repercutindo até os dias atuais, tal como demostrou Murtha 
(2016) ao analisar a intersetorialidade no âmbito das políticas de abastecimento e saneamento. Quanto ao contexto geral da Política de Águas brasileira, o autor faz a seguinte consideração:

A reforma normativa da gestão de recursos hídricos se deu no âmbito dos governos Fernando Henrique Cardoso, sob a égide do ciclo neoliberal de inspiração gerencialista e no bojo da reforma do Estado com diretrizes pró-mercado, em que o país se voltava para uma inserção competitiva no movimento de globalização econômica. (Murtha, 2016, p. 8).

O impacto da reforma gerencial ao longo do tempo acabou de certa forma frustrando os diversos atores sociais que atuaram desde longa data para institucionalização da PNRH. Isso também causou uma quebra das expectativas antes criadas com a promulgação da Constituição Federal de 1988 (CF/88), uma vez que um fato muito relevante a ser considerado por ocasião da referida Carta e relativo à administração pública e suas burocracias, é que, após a redemocratização, o Estado sofreu significativas mudanças e, segundo observam Lotta, Oliveira e Cavalcante (2016, pág. 10), essa mudança "pode ser considerada um divisor de águas para a compreensão do funcionamento do Estado brasileiro".

Não obstante, a reforma gerencial de 1995, lida por alguns autores como uma reinvenção do Estado burocrático weberiano (Pollitt \& Bouckaert, 2011), teve no seu primeiro momento um forte direcionamento à setorialização das políticas públicas, e, como será mais explicitado ao longo deste paper, com fortes impactos na PNRH, em seu arranjo institucional e nos órgãos gestores do sistema. Todavia, por outro lado, em países que fizeram reformas administrativas semelhantes (Pollitt \& Bouckaert, 2011), também produziu discricionariedades e o fortalecimento de determinados segmentos da máquina pública em função dos seus preceitos fundamentais (Howlett, 2011), tal como demostrado no caso brasileiro em Lotta (2015).

A problematização acerca das variáveis da relação entre a PNRH e a reforma gerencial, observando ainda que houve uma primeira tentativa de introdução do gerencialismo em 1967 no Brasil, constituem objeto de análise de primeira grandeza, uma vez que o acesso à água é determinado cada vez mais pela via política, em espaços deliberativos institucionalizados, mas ainda muito submetidos a constrangimentos e limitações institucionais, para a real e efetiva participação dos diversos atores sociais.

Assim sendo, considerando o aspecto metodológico, este paper é fruto de uma pesquisa bibliográfica exploratória e descritiva, acompanhada de uma análise documental, assim como de entrevistas semiestruturadas com atores do sistema de gestão, sob um prisma interdisciplinar, orientado pela seguinte pergunta: quais são as possibilidades analíticas que podem emergir no debate da Política Nacional de Recursos Hídricos, sob a lente teórica da administração pública, e quais caminhos se colocam para renovar este debate?

A PNRH e a administração pública, quando analisados em perspectiva comparada, considerando os avanços e retrocessos dessa relação intrínseca, permitem propor novas abordagens para "velhos" problemas da gestão das águas e seus respectivos fóruns de atuação, especialmente os Comitês de Bacia Hidrográfica (CBHs). Dessa forma, as possibilidades de participação e controle social estabelecidos na Constituição Federal de 1988 (CF/88) e as mudanças experimentadas na administração e suas burocracias desde então abriram espaços para novas abordagens analíticas da PNRH.

Assim, temas como as burocracias relacionais (Marques, 1999, 2000; Lotta, Pires, \& Oliveira, 2014; Abers, 2015), os repertórios de atuação (Abers, Tatagiba, \& Serafin, 2014) e os arranjos institucionais (Lotta \& Favaretto, 2016), colocam-se como promissoras opções teóricas para o entendimento do funcionamento da arena da PNRH. Portanto, é sob esta perspectiva que o presente paper apresenta-se como contribuição.

\section{A reforma tecnocrática e o Plano Nacional de Saneamento}

A reforma da administração pública de 1967 foi a primeira tentativa de introdução do gerencialismo no Brasil, elaborada no berço da ditadura militar, que tinha como objetivo principal aumentar o controle do Governo Federal através de planos e programas em diversos setores. Também diversificou a administração 
com a criação de diversos órgãos estatais, entendida como forma de descentralização da máquina pública (Martins, 1997; Bresser-Pereira, 2011).

Os princípios da reforma eram baseados no planejamento, coordenação, descentralização, delegação de competência e controle. A descentralização preconizada classificou em categorias as empresas a serem criadas ou ainda fortalecidas no âmbito da reforma. Com isso, uma categoria foi especialmente importante, pois consistia nas empresas públicas voltadas à execução de serviços básicos, tais como urbanização, eletricidade, abastecimento e saneamento (Wahrlich, 1974; Bresser-Pereira, 2011; Lima, 1998).

$\mathrm{Na}$ década de 1960, o Brasil tinha uma enorme deficiência em prover os serviços de saneamento e abastecimento. Como solução para esse problema, criou-se o Plano Nacional de Saneamento (PLANASA), que teve como pressupostos a relevância social, a melhoria das condições de saúde e bem-estar, assim como a necessidade de mobilização de recursos financeiros, técnicos e humanos, em níveis federal e estadual, com o objetivo de eliminar o déficit social de saneamento básico, ao mesmo tempo em que se buscava estabelecer uma condição de sustentabilidade financeira dos serviços a serem instalados (Pires, 1979; Bier, Paulini, \& Messenberg, 1988).

Os objetivos e metas do PLANASA foram fixados com base em aspectos estratégicos, tais como a existência de um sistema de planejamento dinâmico e adaptativo, no sentido de instituir um estudo global econômicofinanceiro das companhias que fossem criadas; a escolha (opcional) dos estados, do Distrito Federal e dos territórios como referências para implementação do plano, fortalecimento de suas competências e responsabilidades; a responsabilidade federal na condução do equacionamento financeiro e na coordenação das entidades do sistema, sendo incluída nesse aspecto a questão da qualificação e capacitação dos recursos humanos, desenvolvidas com o apoio da Associação Brasileira de Engenharia Sanitária (ABES); participação da iniciativa privada, através das empresas de projeto, consultorias, empreiteiras e indústrias ligadas ao setor de saneamento básico; e a característica industrial como modelo de prestação de serviços públicos, devidamente remunerados pela população assistida (Pires, 1979; Cynamon, 1986).

Entretanto, conforme observam Barbosa e Silva (2010, p. 66), “A reforma administrativa de 1967 surge como uma das respostas institucionais da tecnoburocracia às demandas de grupos próximos ao regime militar". Nesse contexto, consolida-se uma classe que é especialmente interessante como variável explicativa das instituições da administração pública nesse período (Codato, 2005; Bresser-Pereira, 2011) e dos ainda incipientes sistemas de abastecimento e saneamento (Murtha, 2016), a chamada tecnoburocracia.

Essa classe surgiu durante a reforma oriunda do Decreto-lei 200/67, e que no caso específico dos serviços de saneamento e abastecimento, contextualizada pelo PLANASA (Cynamon, 1986; Marques, 2006), se estabelece como um forte segmento no sistema de gestão hídrica, tendo até os dias atuais forte influência, tanto nos $\mathrm{CBHs}$ quanto nos conselhos de recursos hídricos. Contudo, uma ressalva importante consiste no fato de que a tecnoburocracia aqui analisada é uma classe complexa da administração, não podendo ser confundida e (ou) generalizada com categorias profissionais organizadas, tais como engenheiros ou geólogos, entre outras categorias atuantes no sistema.

\section{A reforma gerencial e a política de recursos hídricos}

A reforma gerencial foi baseada na New Public Management (NPM), surgida no contexto neoliberal ainda na década de 1980 (Brulon, Ohayon, \& Rosenberg, 2012). Quando da sua implantação, recebeu críticas justamente pela sua origem, mas que foram relativizadas, uma vez que suas diretrizes, estabelecidas no Plano Diretor da Reforma do Aparelho do Estado (PDRAE), continuaram sendo implementadas ao longo do tempo nos diversos níveis federativos, independentes da orientação política (Bresser-Pereira, 2010, 2011). Assim, percebida como republicana por uns e neoliberal por outros, o fato é que uma premissa básica da reforma era a ideia de diminuição do aparato estatal, a partir do argumento de que os mercados seriam capazes de se autorregular e estabelecer o equilíbrio econômico, ao mesmo tempo que tal ação daria mais 
fôlego ao Estado, agora menos onerado devido às privatizações necessárias, segundo a visão de seus defensores. Também, somado a isso, considere-se que as ações da reforma gerencial se alinhavam à percepção de organismos internacionais, tais como o Fundo Monetário Internacional (FMI) e o chamado Consenso de Washington, que preconizavam essas ações como uma "solução ótima" para as economias latino-americanas em crise (Andrews \& Kouzmin, 1998; Osborne \& Gaebler, 1995).

A reforma gerencial teve como proposta de inovação a mudança na forma de controle, concentrando foco nos resultados e não no processo, algo característico da administração burocrática clássica. Entretanto, verifica-se que tal ação nunca foi completamente executada devido às implicações jurídicas da atividade prática administrativa, na proteção do interesse público e o ethos burocrático, necessário às democracias de massa (Bresser-Pereira, 2010; Junquilho, 2004; Weber, 1982, 1999).

Ainda segundo Motta (2013, p. 84), “A New Public Management (NPM) apresentou-se com o objetivo primordial de fazer a administração pública operar como uma empresa privada e, assim, adquirir eficiência, reduzir custos e obter maior eficácia na prestação de serviços”. A NPM pode ser lida como um argumento ou ainda uma filosofia, tendo como valores a eficiência e o desempenho. Dessa forma, baseia-se em um conjunto de doutrinas relacionadas a valores prescritivos e justificativas que se incumbem de dar razão às suas prescrições. Portanto, constitui-se como um modelo pós-burocrático, ou uma tentativa de superação da burocracia clássica (Hood \& Jackson 1991; Secchi, 2009). Andrews e Kouzmin (1998) analisam o discurso da NPM no Brasil sob a perspectiva habermasiana e afirmam que este tem como característica intrínseca uma orientação estratégica ou ainda para o sucesso. Neste contexto, observam que essa orientação consiste, de fato, em um modelo conservador, desenvolvido de forma mascarada a partir dos pressupostos da Teoria da Escolha Pública (Public Choice).

O PDRAE (Brasil, 1995, p. 16) traz a seguinte definição: "A administração pública gerencial constitui um avanço e até um certo ponto um rompimento com a administração pública burocrática. Isto não significa, entretanto, que negue todos os seus princípios. Pelo contrário, a administração pública gerencial está apoiada na anterior". A partir dessa afirmação, e também pela análise de outros elementos contidos no PDRAE, verifica-se a semelhança conceitual entre a reforma brasileira e o Neo-weberian State (Pollitt \& Bouckaert, 2011), que, em síntese, é uma nova versão do Estado burocrático weberiano, característico em reformas também baseadas na NPM em outros países do mundo.

O PDRAE baseia-se em três dimensões como estratégia de mudança do aparelho de Estado, a saber: a dimensão institucional-legal, orientada ao aperfeiçoamento do sistema jurídico e legal, por intermédio de emendas constitucionais; a mudança da cultura burocrática predominante para a cultura gerencial; e, por fim, a dimensão da transformação pelo aperfeiçoamento do modelo burocrático vigente, através da modernização da estrutura e dos métodos de gestão (Brasil, 1995).

$\mathrm{Na}$ reforma gerencial, a qualidade representa-se como um elemento fundamental, sendo instrumentalizada pelo Programa da Qualidade e Participação na Administração Pública, tendo como objetivo mudar a cultura burocrática (processo) para a gerencial (resultados). Sendo assim, articula dois conceitos estruturantes:

A gestão pela qualidade é a prática gerencial que apoia a ação de reforma, antecedendo e dando movimento as novas instituições que definem o novo espaço institucional-legal da administração pública, contribuindo para o aumento da capacidade administrativa e financeira (governança) do Estado e conferindo-lhe maior legitimidade (governabilidade). Destarte, implantar a gestão pela qualidade nos órgãos e entidades da administração pública é um fator crítico para o sucesso da reforma do aparelho do Estado. (Bresser-Pereira, 2011, pp. 219-220, grifos do autor).

O PDRAE foi instituído com objetivos globais e específicos muito bem delimitados. Em síntese, os objetivos mais amplos referiam-se ao aumento da capacidade de governar, entendida como ações limitantes da abrangência do domínio de Estado, cujo objetivo é aumentar qualitativamente a eficiência da máquina pública e transferir responsabilidades para estados e municípios. Por conseguinte, o desdobramento disso resultou em quatro áreas-alvo dos objetivos específicos, a saber: o núcleo estratégico; as atividades exclusivas, inclusive regulação; os serviços não exclusivos; e aqueles diretamente voltados à produção de mercado 
(privatizações). Quanto à forma da administração, o chamado núcleo estratégico foi concebido como um misto entre gerencialismo e burocracia clássica; já as demais atividades e serviços foram prescritas para serem totalmente gerenciais. Porém, de forma geral, posteriormente verificou-se que o movimento no sentido de descentralização (Motta, 2013) mostrou-se vir acompanhado de uma forte tendência à centralização, e também de mais e novos processos burocráticos (Kirkpatrick, Ackroyd \& Walker, 2005). Isso corrobora a ideia do já mencionado no conceito do Neo-weberian State.

Assim sendo, em 1997 institui-se o marco da gestão das águas brasileiras, com forte inspiração no modelo participativo e deliberativo francês. A PNRH estruturou toda a gestão das águas no território nacional, colocando os $\mathrm{CBH}$ s como instituições centrais em função dos princípios de participação e descentralização da política de águas brasileira. Os $\mathrm{CBH}$ s são compostos por instituições segmentadas, divididas em poder público, usuários e sociedade civil, orientados à obtenção de consensos sobre o uso do recurso hídrico em um recorte de bacia (bacias) hidrográfica (hidrográficas). Os CBHs também funcionam como o primeiro nível administrativo de resolução de conflitos, operando dentro do Sistema Nacional de Gerenciamento de Recursos Hídricos (SINGREH), o qual consiste em uma estrutura hierárquica com dois níveis, federal e estadual, que visa a coordenar as ações realizadas no âmbito da PNRH (Brasil, 1997, 2012; ANA, 2011).

A PNRH representou um reconhecido avanço na gestão hídrica brasileira. Sua proposta, mesmo nos dias atuais, é bastante inovadora, inclusive por se contrapor às práticas tecnicistas e centralizadoras de gerenciamento em períodos passados (Jacobi, 2004). Porém, ao observar a sua criação em uma linha do tempo, é possível perceber que, muito embora apresente-se como a materialização do pleito de espaços deliberativos pauta de diversos movimentos sociais ao longo das décadas de 1980 e 1990, a partir de um cenário sociopolítico redemocratizado pela Constituição de 1988 (Jacobi, 2009; Dagnino, 2002; Abers \& Jorge, 2005), quando da sua implementação, o horizonte que se colocava era formado por entes públicos moldados pela reforma gerencial. Portanto, a dinâmica implícita era orientada a responder problemas específicos da economia e da estrutura de Estado na ótica do neoliberalismo (Pollitt \& Bouckaert, 2011), conforme já mencionado, isso se dava com a assimilação de elementos oriundos da iniciativa privada, a subjetiva ideia de qualidade na ótica neoliberal, assim como o resgate de elementos weberianos, como forma de garantir o controle da máquina pública.

Nesse contexto, então, constata-se que a PNRH, já no seu início, submeteu-se a uma narrativa, com uma finalidade pré-estabelecida, que possuía sua própria percepção sobre as políticas públicas. Logo, a implementação da gestão das águas brasileira tornou-se, sobretudo, uma tarefa conflituosa e complexa.

\section{As agênCIAS REguladoras no ÂMbito do SINGREH}

No âmbito geral do PDRAE, existiam três ações a serem realizadas pelo Estado: publicização, privatização e a terceirização (Bresser-Pereira, 2011). Dito isso, e considerando o objetivo orientado à produção de mercado, surge a necessidade de "Reorganizar e fortalecer os órgãos de regulação dos monopólios naturais que forem privatizados" (Brasil, 1995, p. 47). Logo, são criadas as chamadas agências reguladoras. Por definição, retirada do direito administrativo, essas instituições compreendem "qualquer órgão da Administração Direta ou entidade da Administração Indireta com função de regular a matéria específica que lhe está afeta” (Di Pietro, 2014, p. 540).

Assim, na perspectiva da PNRH, duas agências são especialmente importantes: primeiramente, a Agência Nacional de Águas (ANA), que consiste em uma autarquia sob regime especial, com autonomia administrativa e financeira, originalmente vinculada ao Ministério de Meio Ambiente (ANA, 2012). Suas competências estão relacionadas à implementação da PNRH e à articulação no âmbito do SINGREH, também desempenhando o papel executivo, de assessoramento, aos $\mathrm{CBH}$ instituídos nas bacias hidrográficas, ainda sem o instrumento de cobrança pelo uso de recursos hídricos implementado (ANA, 2012). 
A ANA foi criada como um desdobramento da PNRH. A agência difere das demais, uma vez que suas atribuições têm características muito específicas, tal como disciplinar a implementação, a operacionalização, o controle e a avaliação dos instrumentos da PNRH, fazendo articulação com diversos entes e instituições, em diversos níveis federativos. Como exemplo disso, podemos citar os ministérios de Meio Ambiente, Minas e Energia, assim como outras agências reguladoras, como a Agência Nacional de Energia Elétrica (ANEEL) e a Agência Nacional de Transportes Aquaviários (ANTAQ), expandindo o ambiente de gestão. Além disso, é atribuição da agência coordenar a implementação da Política Nacional de Segurança em Barragens (Brasil, 2000; IPEA, 2019; ANA, 2019; MMA, $2016^{[1]}$ ).

Contudo, Fadul et al. (2013) observam que o papel da ANA é distinto das demais agências. Isso se dá em função de que a água é um bem de domínio público, pois não houve privatização. Também, por suas funções serem relacionadas à implementação de uma política, como é o caso de estimular a criação de CBHs. Dessa forma, observa-se que as características de atuação são mais equivalentes às de uma agência de águas (executiva), do que de um ente de regulação no seu sentido estrito. Desse modo, é possível acrescentar:

Assim, entende-se que tendo recebido atribuições - que como salientado poderiam ser facilmente atribuídas por outros agentes - como que para, fragilmente, justificar sua criação, a Agência Nacional de Águas deve sua existência muito mais ao contexto histórico de reforma do Estado e das privatizações que desencadeou um processo de agencificação, entendido como um processo de difusão e proliferação de agências reguladoras independentes, do que, efetivamente, a emergência de um ente regulador nascido da aplicação de elementos técnicos, conceituais e teóricos da regulação”. (Fadul et al., 2013, p. 14).

Outro ente importante no sistema de gestão hídrica brasileiro compreende a já citada ANEEL. Esta é responsável por gerir a Compensação Financeira pela Utilização de Recursos Hídricos (CFURH), que consiste em um valor percentual pago pelas concessionárias de geração de energia hidrelétrica e pelos royalties de Itaipu. Um ponto central a ser observado no contexto do setor elétrico consiste na sua própria institucionalização. Goldenberg e Prado (2003) explicam que o debate sobre o setor elétrico da década de 1990 girava em torno de questões amplas, tais como a globalização da economia e suas consequências para o mercado, e a quebra do paradigma das fronteiras geográficas e de como isso impactava as políticas cambiais, monetária e tributária. Estes autores ainda observam que um dos pontos norteadores na tomada de decisão para criação da agência foi uma tendência crescente de internacionalização do Estado, que pode ser percebido como:

[...] a disseminação do liberalismo, promovida especialmente por agências multilaterais (Bird, BID, FMI), cuja síntese ficou conhecida como Consenso de Washington. Essa visão pregava, por exemplo, a liberalização dos preços, do comércio e do investimento estrangeiro, a desregulamentação e a privatização em grande escala, como medidas a serem adotadas em países como o Brasil” (Goldenberg \& Prado, 2003, p. 223)

Assim, a estrutura do sistema baseava-se na criação de uma agência reguladora, a ANEEL, e também por mais duas organizações, a saber: o Operador Nacional do Sistema Elétrico (ONS), que constitui pessoa jurídica de direito privado, sob a forma de associação civil sem fins lucrativos, tendo a função de coordenação, controle e operação das instalações de geração e transmissão de energia elétrica no Sistema Interligado Nacional (SIN), mediante fiscalização da ANEEL. Já o segundo, o Mercado Atacadista de Energia Elétrica (MAE), que em 2004 foi substituído pela Câmara de Comercialização de Energia Elétrica (CCEE) é uma instituição que foi criada para viabilizar as operações comerciais (leilões) de energia em todo o SIN (CCEE, 2016; Goldenberg \& Prado, 2003; ANA, 2012; Trindade \& De Oliveira, 2013).

Em Santana (2002), são identificadas três fases distintas da criação das agências reguladoras nos moldes do PDRAE. A primeira fase corresponde à quebra do monopólio do Estado, com destaque para telefonia, eletricidade e petróleo; na segunda fase, as agências exercem a sua função de regulação em um ambiente competitivo, já na perspectiva de mercado; a terceira fase compreende o momento em que a característica de regulação é "perdida", ou, ainda, é modificada em função dos objetivos específicos voltados para cada setor, a exemplo da própria ANA, mas também da Agência Nacional do Cinema (ANCINE). Todavia, quando 
observado sob outro prisma, tem-se que a regulação abriga uma dicotomia, que se desenvolve a partir de duas perspectivas quanto à sua finalidade, tal como observado a seguir:

(...) a duas ideias fundamentais: uma, é a ideia de equilíbrio (de estabilidade): a regulação de um sistema (complexo) compreende a manutenção do equilíbrio deste sistema e a finalidade primordial da regulação é assegurar seu funcionamento correto. A outra remete ao conceito primitivo de regulação que expressava a dominação: é a ideia de controle. (Fadul, 2007, p. 18).

A provocação colocada por Fadul (2007) expressa o dilema enfrentado pela ANA na condição de implementadora de uma política pública complexa, como a PNRH. A forma institucional da ANA foi optada após um amplo debate nas instâncias do SINGREH, que se mostrou como a melhor opção do ponto de vista institucional (oportunidades e limitações). Isso também se deu em função da magnitude da missão que teria no sistema de gestão (MMA, 2016).

\section{ATORES ORIGINADOS DA PUBLICIZAÇÃo No ÂMBITO Do SINGREH}

A reforma gerencial brasileira surgiu a partir de uma conjuntura interna muito específica, e também da percepção e influência de organismos internacionais, tal como o FMI, OCDE e também o Banco Mundial, sendo este último defensor da descentralização das políticas públicas. Nesse contexto, verifica-se que desde o início da década de 1980 os movimentos sociais reivindicavam espaços de deliberação. Isso foi um forte elemento na institucionalização de políticas públicas ao longo da década de 1990, com a criação de diversos conselhos gestores, em diversas áreas, e que, somado ao movimento de publicização, promoveram uma reestruturação de diversos segmentos da sociedade em torno das várias pautas, especialmente da questão ambiental (Andrews \& Kouzmin, 1998; Dagnino, 2002; Brasil, 1995; Bresser-Pereira, 2011; Abers \& Jorge, 2005).

Conforme já mencionado, no horizonte do PDRAE, além das ações relativas à privatização de determinados setores, existiam também as ações de "publicização", uma vez que, na perspectiva da reforma, deveriam haver quatro tipos possíveis de propriedade, orientados pelo critério de finalidade e também pelo regime jurídico. Assim, a propriedade privada seria aquela voltada para a obtenção de lucro, ou, ainda, para fins privados. Por outro lado, existem as propriedades públicas, que estão voltadas para o atendimento do interesse público; as corporativas, que compreendem aquelas que se destinam a defender os interesses de grupos específicos; e, por fim, a quarta classe, que compreende a pública não estatal, que também pode ser entendida como uma forma de controle social, segundo os idealizadores da reforma (Bresser-Pereira, 2011).

No âmbito do PDRAE e do Programa Nacional de Publicização (PNP), surge o conceito das Organizações de Serviço Públicas não estatais (OSPNEs), englobando parte das organizações do chamado Terceiro Setor (Bresser-Pereira, 2010, 2011). Nesse universo de organizações, figuravam as chamadas Organizações Sociais (OS), menos importantes no escopo do presente paper, e também a Organização da Sociedade Civil de Interesse Público (OSCIP), instituída pela Lei Federal n. 9.790/99, e regulamentada pelo Decreto n. 3.100/99, atualmente com modificações acrescidas pela Lei Federal n. 13.019/14. Assim sendo,

Trata-se de qualificação jurídica dada a pessoas jurídicas de direito privado, sem fins lucrativos, instituídas por iniciativa de particulares, para desempenhar serviços sociais não exclusivos do Estado com incentivo e fiscalização pelo Poder Público, mediante vínculo jurídico instituído por meio de termo de parceria. (Di Pietro, 2014, p. 584).

Tal como visto nos parágrafos anteriores, através dessas qualificações organizacionais foram estabelecidas as principais figuras daquilo que foi definido como Terceiro Setor no seio da reforma gerencial e, portanto, na experiência neoliberal brasileira. Importante ainda destacar que o Terceiro Setor também foi composto por diversas organizações generalizadas, como as organizações não governamentais (ONGs), mas não necessariamente qualificadas como OSCIPs. As ONGs que surgiram na área ambiental, mais fortemente a partir da década de 1970, igualmente se submeteram a uma lógica burocrática-operacional, até pela 
necessidade de acessar recursos para atingir seus objetivos voltados ao interesse público (ANA, 2012; Trindade \& De Oliveira, 2013; Dagnino, 2002; Alves \& Koga, 2006).

Nos CBHs, o segmento denominado sociedade civil é parcialmente constituído por ONGs, em sua grande maioria, classificadas como defensoras de interesses difusos e coletivos da sociedade e atuação em defesa dos recursos hídricos. Eventualmente, essas organizações tornam-se OSCIPs, porém, todas tendo uma representação muito característica sob a perspectiva da governança (Ibidem).

Por outro lado, a ANA, desde de longa data, vem investindo em editais que buscam trazer entidades com a qualificação de OSCIP para atuarem como agências delegatárias, e também outras atividades no sistema[v]. Estas agências, que são secretarias executivas dos $\mathrm{CBH}$ s, têm sua criação vinculada diretamente a estes, conforme artigos 41 e 42 da PNRH. São regidas pela Lei Federal n. 10.881/04, e têm sempre vínculo estabelecido com ANA com a interveniência do CBH em questão, em sua maioria, através um contrato de gestão (Brasil, 1997; ANA, 2012, 2014; Trindade \& De Oliveira, 2013).

Em teoria, as agências delegatárias desfrutam de liberdades de gestão organizacional. Isso se dá à medida que possuem autonomia financeira e administrativa no que diz respeito ao custeio não regulado pela Lei Federal n. 8.666/93 (licitações e contratos), uma vez que o artigo nono da Lei Federal n. 10.881 define que cabe à ANA definir as regras para utilização dos recursos nessa categoria de ente, buscando, assim, viabilizar as atividades e a gestão das agências delegatárias. Atualmente, a forma jurídica mais comum entre as agências delegatárias constitui na organização civil e sem fins lucrativos, porém, não qualificada como OSCIP. Isso se dá muitas vezes por opção da própria organização, uma vez que a atividade exercida, devido à sua natureza, já confere o título de utilidade pública. Dessa maneira, na prática, o molde jurídico-institucional das OSCIPs é emulado nas agências delegatárias (ANA, 2012, 2014; AGEVAP, 2016).

Percebe-se, assim, que o ambiente institucional da reforma gerencial estabeleceu condiçóes de partida à implementação da PNRH. Um ponto relevante nesse sentido consiste essencialmente em compreender como a reforma gerencial propiciou condições favoráveis ou desfavoráveis às instituições, grupos e atores que viriam a compor a arena de recursos hídricos a partir da criação da PNRH, pois, no momento inicial, dois pontos eram especialmente interessantes na perspectiva de uma análise comparada, mas que ecoam até os dias atuais. Estes pontos são: a tensão que se instalou entre a expectativa de maior democracia na gestão da água por parte dos movimentos sociais e a institucionalização dos $\mathrm{CBH}$; e, em paralelo, a pressão dos agentes econômicos, ávidos por recursos para suas atividades industriais, visando a segurança jurídica dos empreendimentos que teriam a água como insumo, a fim de garantir regras claras de acesso ao recurso em um mercado globalizado.

\section{A ADERÊNCIA DA PNRH À REFORMA GERENCIAL E OS ANTAgONISMOS No CAMPo DA GOVERNANÇA}

Tal como demostrado nos três tópicos anteriores, o arranjo institucional da PNRH foi montado, em parte, por figuras institucionais oriundas da reforma gerencial que trazem consigo uma lógica intrínseca. Em síntese, a ideia da reforma de 1995 foi buscar a introdução de elementos de controle, tentando assimilar o padrão neoliberal de suposta eficácia da iniciativa privada, ao mesmo tempo em que buscava reduzir a ação do Estado em setores estratégicos de interesse do mercado, indo ao encontro dos interesses de uma economia global. $\mathrm{O}$ desdobramento prático da reforma foi a especialização, que, no caso principalmente das agências reguladoras, independente do momento e finalidade da sua criação, resultou na setorialização de diversas políticas públicas e na geração de mais burocracia e sua variante, a tecnoburocracia, no caso já estabelecida no Brasil desde a reforma administrativa de 1967, tendo como exemplo a estruturação tecnicista do PLANASA (Bier, Paulini, \& Messenberg, 1988; Murtha, 2016)

A PNRH, desde a sua criação, sofre grande impacto, uma vez que sua implementação perpassou um diálogo com uma orientação institucional muito específica e, de certa forma, conflitante com seus próprios 
princípios institucionais. Além disso, a reforma de 1995 como um plano de Estado possui um conjunto de valores oriundos de uma percepção externa, norteada por uma visão subordinadora das economias periféricas (Murtha, Castro, \& Heller, 2015); isso se dá especificamente ao se falar de abastecimento e saneamento, com consequências diretas para a concepção das referidas políticas setoriais (Murtha, 2016). Portanto, a estruturação do atual sistema de gestão de recursos hídricos ocorreu, em grande parte, pelo prisma do NPM, com suas diretrizes voltadas ao mercado, que se fizeram presentes na sua concepção e em seu desenvolvimento. Nesse contexto, Silva (2011), ao analisar um comitê federal na perspectiva da participação, afirma que dada natureza da reforma gerencial, a consequência para a gestão, foi a produção de uma deficiência recorrente no cumprimento dos fundamentos da PNRH. Isso é decorrente da dinâmica desigual estabelecida entre os agentes econômicos, as instituições do Estado e os atores dos movimentos sociais.

Contudo, faz-se muito importante observar a convergência entre reforma administrativa de 1995 e a PNRH, uma vez que a ideia de renovação e novas propostas de arranjos institucionais à época colocavamse como possibilidades muito bem recebidas, tanto para o governo como para os diversos atores interessados na instituição da Política de Águas brasileira. Assim, o ideal seguido pelos diversos “... setores da sociedade brasileira, desde burocratas até movimentos sociais, certamente deu legitimidade à ideia de se criar conselhos descentralizados" (Abers \& Jorge, 2005, pp. 20-21).

Ainda segundo Abers e Jorge (2005), o próprio conceito de comitê colegiado apresentava-se como uma ideia compartilhada por diversos outros atores com grande influência na institucionalização da PNRH e na consequente criação de CBHs. Importa ainda pontuar que comitês e conselhos são a base da política francesa de gestão das águas, a qual serviu ao modelo brasileiro. Portanto, o próprio histórico da implantação da PNRH, visto pelos diversos trabalhos já publicados a respeito, sinalizam um debate mais aprofundado sobre os próprios limites dos instrumentos do arranjo institucional da PNRH quanto às suas capacidades democráticas e de efetiva participação (Fracalanza, 2006; Silva, 2011; Trindade \& Fracalanza, 2015; Abers et al., 2009).

O conceito de governança, no contexto da reforma gerencial, consiste na articulação do poder, entendida como a capacidade governativa que perpassa a ideia de dominação e controle, sendo este executado em nível institucional e operado por organizações concebidas para esse fim. É nesse ponto que se situa um conflito crasso e estrutural entre a essência da reforma administrativa de 1995 e os princípios da PNRH.

Ao revisitar o conceito pela ótica de organismos internacionais que influenciaram a reforma, o termo governança aparece em documentos e publicações do Banco Mundial, tendo ao menos duas definições: uma mais ampla, que pode ser entendida como o "exercício da autoridade, controle e administração do poder governamental” (World Bank, 1992, p. 03); uma segunda definição, mais específica, consiste “... na maneira pela qual o poder é exercido na administração da economia e da sociedade de um país, com vistas ao desenvolvimento" (Ibidem).

Por outro lado, é importante buscar a definição de governança, agora no contexto da gestão hídrica, que, segundo Heinelt et al. (2002 apud Jacobi, 2009, p. 11, tradução minha, grifos do autor) é: “. . caracterizado por uma combinação de estruturas hierárquicas, dinâmicas participativas, ação associativa, mecanismos de mercado, sendo baseada principalmente em uma cultura de diálogo, a negociação, a cidadania ativa e fortalecimento institucional". Ou, ainda, a governança hídrica refere-se a um "conjunto de sistemas político, social, econômico e administrativo que visam desenvolver e gerir os recursos hídricos e serviços de abastecimento, em diferentes escalas da sociedade" (Global Water Partnership, 2002, p. 14, grifos do autor).

A dissonância de percepções deve-se, primeiramente, à própria fragilidade do conceito, já que é bastante polissêmico, e, a depender do interlocutor, ideias completamente antagônicas podem ser por ele conotadas. Assim, ora se manifesta pelo controle, no contexto weberiano, exercido por instituições burocráticas, ora ocorre pela participação de diferentes entes e atores, presumindo a ocorrência de cooperação voluntária entre eles. 
A PNRH desenvolve-se em diferentes níveis federativos e camadas sociais nas diversas arenas. $\mathrm{O}$ arranjo institucional funciona mediante múltiplos conflitos e contradições, que se estabeleceram não somente no seu início, mas, também, ao longo do processo de implementação. Os CBHs, como instrumentos do arranjo institucional também fortemente arraigados pela lógica neoliberal, sempre se colocam de forma dúbia, pois, para além do seu sentido prescrito, são permeados por instituições que se manifestam pelo poder do capital privado, ou, ainda, pela burocracia de Estado, percebida por um prisma marxista. Nesse sentido, funcionam em alguns momentos como aparelhos de dominação, porém, sempre dependentes de um meio de legitimação, tal como em Weber ([1912] 2012). Contudo, é justamente esse elemento que se coloca como diferencial na perspectiva da participação social, uma vez que a inserção da sociedade civil institucionalizada é o principal constituinte do colegiado, que garante a sua legitimação enquanto fórum deliberativo.

\section{UM DEBATE SOBRE A IMPLEMENTAÇÃO E BUROCRACIAS}

Políticas públicas são complexas e de difícil definição (Souza, 2006), e a política de águas brasileira que contém em si uma reforma (Abers \& Keck, 2017) não é diferente. A PNRH reestruturou todo um ambiente de gestão das águas como recurso hídrico, redefinindo uma complexa arena sociopolítica, que, no caso brasileiro, começa a se formar ainda durante a ditadura militar, na década de 1960. Assim, igualmente a outras políticas públicas que se propõem a redistribuir recursos, tal como visto nas tipologias de Lowi (1972), o ambiente de gestão de águas brasileiro desenvolve-se de maneira tendenciosamente conflituosa.

Muitos dos conflitos têm na sua origem a própria complexidade do tema água, materializado pela disparidade de acepção, que, sob determinados aspectos, expressam signos opostos de pouca ou nenhuma conciliação. É notória a diversidade de atores, culturas, valores e referenciais no debate sociopolítico da água no Brasil, facilmente verificado mesmo nos $\mathrm{CBH}$ s, em que a participação é institucionalizada. Dessa maneira, esta complexidade intrínseca mostra-se como importante variável de implementação, avaliação e reformulação da PNRH, considerando ainda o caráter didático do processo.

A implementação da PNRH, após mais de 20 anos de sua criação, ainda se coloca como um grande desafio ao acesso à água bruta em termos sociopolíticos. Assim, mediante a perspectiva analítica proposta neste paper, é importante atentar para alguns pontos, sendo o primeiro e mais característico o próprio arranjo institucional da PNRH, que se apresenta como uma justaposição de perspectivas contrárias, uma vez que o SINGREH, como sua espinha dorsal, surge como uma estrutura hierárquica com claro predomínio do Governo Federal (Murtha, 2016), em que pese o CNRH, ente de maior grau no sistema, ser um conselho participativo. Porém, legitima-se pelo fiel cumprimento das instituições jurídicas (leis, decretos e regulamentos), pelo rito burocrático, e sua composição e estruturação organizacional - principalmente das câmaras técnicas, característico de uma estrutura de dominação burocrática, tal como visto em Weber (1982, 1999).

O conceito de gerenciamento do SINGREH remete à ideia de controle, de modo a conseguir resultados previsíveis e orientados a um fim específico, guardando então uma identificação com a ideia de dominação, e é essa orientação que direciona a análise para modelos top-down. Pontua-se também que nessa condição temse uma espécie de antítese da emancipação habermasiana (Andrews \& Kouzmin, 1998). Por sua vez, e de maneira contraditória, os CBHs colocam-se como fóruns deliberativos e participativos, de gestão. Quanto a isso, é importante fazer atenção ao termo "gestão", pois este abarca tanto o conceito de gerenciamento como também elementos externos, mas importantes sob aspectos políticos, sociais, ambientais. Os CBHs também são locais onde os usuários e os movimentos sociais participam da gestão, estabelecendo uma identificação com modelos bottom-up de análise.

Hill (2006) observa que na análise de determinadas políticas públicas, os modelos top-down ou bottomup podem ser usados simultaneamente, sem prejuízo à análise, inclusive trazendo benefícios. Logo, duas possibilidades mostram-se muito promissoras à medida que, além das características já mencionadas, o 
arranjo institucional guarda características híbridas (Trindade, 2019). Nesse caso, algumas chaves analíticas podem ser exploradas, tendo como foco os instrumentos, os mecanismos de funcionamento, ou, mais ainda, as capacidades desenvolvidas, tal como exemplificado em Trindade (2019, 2020) sobre o Projeto de Aperfeiçoamento de Ferramentas Estaduais de Gestão de Recursos Hídricos, no Âmbito do Progestão. Por outro lado, os recortes de gestão, ou, ainda, as diversas arenas específicas, constituem um ambiente no qual diversos atores interagem a partir de condições muito específicas, tal como visto em Trindade (2019) ao analisar uma categoria definida de burocrata; ou, ainda, em Mancilla (2019), sobre o nível de influência dos atores participantes em múltiplos fóruns participativos.

O gerencialismo, perseguido como modelo pelas duas últimas grandes reformas da administração pública brasileira, teve como resultado a consolidação de uma burocracia de Estado heterogênea, em seus diferentes níveis federativos, contribuindo para o estabelecimento de diferentes marcos, aos quais construíram paralelamente a historicidade da gestão hídrica no Brasil. Assim, da tecnoburocracia criada no berço do regime militar à criação do PLANASA, e da reforma gerencial, como uma reinvenção do Estado weberiano, a PNRH coloca-se sob diferentes perspectivas analíticas.

A burocracia, então, emerge como sendo um campo teórico relevante, tanto para compreender diversos processos de dominação e limitação das potencialidades participativas e descentralizadoras nos CBHs e Conselhos no âmbito do SINGREH quanto para compreender como a PNRH desenvolve-se pela ação de burocratas de diferentes categorias, e suas relações e vínculos com outras categorias e classes de atores dos diversos setores. Não obstante, observa-se, ainda, que a burocracia se apresenta de forma emergente a partir das variáveis observadas na presente pesquisa.

Assim, encerra-se o presente paper, que buscou, através de uma estruturação narrativa da bibliografia relacionada ao tema e dos demais meios de investigação, propor novas possibilidades de análise da PNRH. Reitera-se a importância dos arranjos institucionais e suas variáveis, por abrirem espaço para estudos que investiguem a forma como o Estado cria capacidades de implementação da gestão das águas, e quais os papeis desempenhados pelas diferentes categorias de atores nesse processo. Nesse contexto, as burocracias, entendidas como domínios específicos da administração pública, podem ser também recortes de análise sob diferentes aproximações metodológicas, permeando diferentes tipos de análise.

\section{REFERÊNCIAS}

Abers, R., Jorge, K. D. (2005, dezembro) Descentralização da gestão da água: por que os comitês de bacia estão sendo criados? Ambient. soc., Campinas, 8 (2), 99-124. Recuperado, em 24/05/2016, de: http://www.scielo.br/scielo. php?script=sci_arttext\&pid=S1414-753X2005000200006\&lng=en\&nrm=iso.

Abers, R. N., Formiga-Johnsson, R. M., Frank, B., Keck, M. E., Lemos, M. C. (2009). Inclusão, deliberação e controle: três dimensões dedemocracia nos comitês e consórcios de bacias hidrográficas no Brasil. Ambiente \& Sociedade, 12(1), 115-132.

Abers, R. N. (2015). Ativismo na burocracia? O médio escalão do Programa Bolsa Verde. Burocracia de médio escalão: perfil, trajetória e atuação. Brasília: ENAP, 143-175.

Abers, R., Serafim, L., Tatagiba, L. (2014). Repertórios de interação Estado-sociedade em um Estado heterogêneo: a experiência na era Lula. Dados, 57(2), 325-357.

Abers, R. N., Keck, M. E. (2017). Autoridade prática: ação criativa e mudança institucional na política das águas do Brasil.

Alves, M. A., Koga, N. M. (2006, dezembro) Brazilian nonprofit organizations and the new legal framework: an institutional perspective. BAR, Braz. Adm. Rev, Curitiba, 3 (2), 68-83.

Agência Nacional de Águas. (2002). Evolução da organização e implementação da gestão de bacias no Brasil. Conferência Internacional de Órgãos de Bacia. Madri: ANA.

Agência Nacional de Águas. (2011). O Comitê de Bacia Hidrográfica: o que é e o que faz? Brasília: SAG. 
Agência Nacional de Águas. (2012). Alternativas organizacionais para gestão de recursos hídricos. Brasília: ANA. Agência Nacional de Águas. (2014) Agência de Água - o que é, o que faz e como funciona Brasília: ANA. Agência Nacional de Águas (2019). Recuperado de: http://progestao.ana.gov.br/.

Alves, M. A., Koga, N. M. (2006). Brazilian nonprofit organizations and the new legal framework: an institutional perspective. Revista de Administração Contemporânea, 10(SPE), 213-234.

Andrews, C. W., Kouzmin, A. (1998) O discurso da nova administração pública. Lua Nova, 45(1), 97-129.

Barbosa e Silva, L. A Reforma Administrativa de 1967. In: Andrews, Cristina W., Bariani, Edson (2010). Administração Pública no Brasil: breve história política. São Paulo: Editora Unifesp.

Barth, F. T. (1996) A Recente experiência brasileira de gerenciamento de recursos hídricos. Cadernos Fundap, 20, 5975.

Bier, A. G., Paulini, L. M., Messenberg, R. P. (1988, abril) A Crise do saneamento no Brasil: reforma tributária, uma falsa resposta. Pesq. Plan. Econ, 18 (1), 161-196.

Brasil. (2000) Lei no 9.984. Dispõe sobre a criação da Agência Nacional de Águas. Recuperado, em 05/05/2016, de: http://www.planalto.gov.br/ccivil_03/leis/L9984.htm;.

Brasil. (1997). Lei no 9.433, de 8 de janeiro de 1997. Institui a Política Nacional de Recursos Hídricos, cria o Sistema Nacional de Gerenciamento de Recursos Hídricos, regulamenta o inciso XIX do art. 21 da Constituição Federal, e altera o art. $1^{\circ}$ da Lei $n^{\circ} 8.001$, de 13 de março de 1990, que modificou a Lei ${ }^{\circ} 7.990$, de 28 de dezembro de 1989. Diário Oficial da União.

Brasil (1995). Plano Diretor da Reforma do Aparelho do Estado. Ministério da Administração Federal e da Reforma do Estado, Brasília.

Brasil. (2000). Lei no 9.984, de 17 de julho de 2000. Dispõe sobre a criação da Agência Nacional de Águas-ANA, entidade federal de implementação da Política Nacional de Recursos Hídricos e de coordenação do Sistema Nacional de Gerenciamento de Recursos Hídricos, e dá outras providências.

Bresser-Pereira, L. C. (2010). Democracia, estado social e reforma gerencial. Revista de Administração de Empresas, $50(1), 112-116$.

Bresser-Pereira, L. C. (2011) Reforma do Estado para a Cidadania: a reforma gerencial brasileira na perspectiva internacional, São Paulo: Editora 34.

Brulon, V., Ohayon, P., Rosenberg, G. (2012). A reforma gerencial brasileira em questão: contribuições para um projeto em construção. Revista do Serviço Público, v. 63, n. 3, p. 265-284.

Câmara de Comercialização de Energia Elétrica (CCEE). Recuperado de: http://www.ccee.org.br/portal/faces/page s_publico/quem-somos/historia?_adf.ctrl-state $=191$ wdrmxev_5\&_afrLoop $=1228648569468650 \# !$ !.

Codato, A. N. (2005, novembro). Uma história política da transição brasileira: da ditadura militar à democracia. Rev. Sociol. Polit., 25, 83-106

Cynamon, S. E. (1986, junho). Política de Saneamento: proposta de mudança. Cad. Saúde Pública, 2 (2) 41-149.

Dagnino, E. Sociedade Civil, Espaços públicos e a construção democrática no Brasil: limites e possibilidades”. In: Dagnino, E. (2002) Sociedade Civil e espaços públicos no Brasil, São Paulo: Paz e Terra.

Di Pietro, M. S. Z. (2014). Direito administrativo, São Paulo: Atlas.

Fadul, E., Terso, V., Fabricio, Flavio, C., Lucas, S. (2013) A Agência Nacional de Águas e a Regulação Recursos Hídricos. Anais de evento - XXXVII Encontro da ANPAD, Rio de Janeiro.

Fadul, E. Dinâmicas contemporâneas na regulação de serviços públicos. In: Peci, Alketa. (2007) Regulação no Brasil: Desenho, governança, avaliação, São Paulo: Editora Atlas.

Fracalanza, A. P. Modelo de Gestão das Águas: o caso do Sistema Cantareira (São Paulo - Brasil). I Simpósio de Recursos Hídricos do Sul-Sudeste. Curitiba: 2006.

Global Water Partnership. Annual Report, 2002.

Goldenberg, José, Prado, Luiz, Tadeu, Siqueira. (2003, novembro) Reforma e crise do setor elétrico no período FHC. Tempo Soc., 15 (2), 219-235. 
Hill, M. Implementação uma visão geral. Políticas Públicas. Brasília., 2006.

Hood, C., Jackson, M. W. (1991) Administrative argument. Aldershot, Hants, England, USA: Dartmouth Pub.

Howlett, M. (2011). Public managers as the missing variable in policy studies: An empirical investigation using Canadian data. Review of Policy Research, 28(3), 247-263.

Ipea. Relatório síntese do II seminário de acompanhamento do Projeto Ferramentas de Gestão, 2019.

Jacobi, P. R. A gestão Participativa de bacias hidrográficas no brasil e os desafios do fortalecimento de espaços públicos colegiados. In: Coelho, Vera Schattan P. (2004)Participação e deliberação: teoria democrática e experiências institucionais no Brasil contemporâneo, São Paulo: Editora 34.

Jacobi, P. R. (2009) Governance - Water Governance, mimeo, 2009.

Junquilho, G. S. (2004) Nem "burocrata” nem "novo gerente": o "caboclo" e os desafios do Plano Diretor de Reforma do Estado no Brasil do real. Revista de Administração Pública, 38, (1), 137-156.

Kirkpatrick, I., Ackroyd, S., Walker, R. (2005). The new managerialism and public service professions. Hampshire: Palgrave Macmillan.

Lima, O. B., Junior (1998, abr-jun). As reformas administrativas no Brasil: modelos, sucessos e fracassos. Revista do Serviço Público, 49, (2),3-131.

Lotta, G. S., Pires, R. R. C., Oliveira, V. E. (2014). Burocratas de médio escalão: novos olhares sobre velhos atores da produção de políticas públicas.

Lotta, G. S. (2015). Burocracia e implementação de políticas de saúde: os agentes comunitários na Estratégia Saúde da Família. SciELO-Editora FIOCRUZ.

Lotta, G., Favareto, A. (2016). Os Arranjos Institucionais dos Investimentos em Infraestrutura no Brasil: uma análise sobre seis grandes projetos do Programa de Aceleração de Crescimento (No. 2253). Texto para Discussão.

Lotta, G., Oliveira, V., Cavalcante, P. (2016). Do Insulamento Burocrático à Governança Democrática: transformações institucionais e a burocracia no Brasill. 10 Encontro da Associação Brasileira de Ciência Política.

Lowi, T. J. (1972). Four systems of policy, politics, and choice. Public administration review, 32(4), 298-310.

Mancilla, G. M., Bodin, Ö. (2019). Participation in multiple decision making water governance forums in Brazil enhances actors' perceived level of influence. Policy Studies Journal, 47(1), 27-51.

Marques, E. C. (1999). Redes sociais e instituições na construção do Estado e da sua permeabilidade. Revista Brasileira de Ciências Sociais, 14(41), 45-67.

Marques, E. C. (2000). Estado e redes sociais: permeabilidade e coesão nas políticas urbanas no Rio de Janeiro. Rio de Janeiro: Editora Revan.

Marques, E. C. (2006). Redes sociais e poder no Estado brasileiro: aprendizados a partir de políticas urbanas. Revista Brasileira de Ciências Sociais, 21(60), 15-41.

Martins, L. (1997) Reforma da Administração Pública e cultura política no Brasil: uma visão geral. Brasília: Cadernos ENAP, 8, (61).

Motta, P. R. M. (2013, fevereiro). O estado da arte da gestão pública. Rev. adm. Empres, 53 (1), 82-90.

Murtha, N. A. (2016) Intersetorialidade nas politicas brasileiras de saneamento e de recursos hidricos em um contexto de reformas. Tese de doutorado, Universidade Federal de Minas Gerais.

Murtha, N. A., Castro, J. E., Heller, Léo. (2015, setembro). Uma perspectiva histórica das primeiras políticas públicas de saneamento e de recursos hídricos no brasil. Ambient. Soc, 18, (3), 193-210.

Osborne, D; Gaebler, T. Reinventando o governo. 6. ed. Brasília: MH Comunicação, 1995.

Pires, I. M. (1979). PLANASA: avaliação dos Resultados e Perspectivas. Revista DAE, 121(1212), 1-20.

Pollitt, C., Bouckaert, G. (2011). Public Management Reform: A Comparative Analysis-New Public Management, Governance, and the Neo-Weberian State. Oxford University: Editora Oxford.

Santana, A. (2002) O processo de agencificação: pressupostos do modelo brasileiro e Balanço da experiência. Balanço da Reforma do Estado no Brasil. A Nova Gestão Pública, 6. 
Secchi, L. (2009) Modelos organizacionais e reformas da administração pública. Rev. Adm. Pública, 43(2), 347-369

Silva, M. V. D. de C. (2011) O (s) significado(s) da participação dos usuários das águas e da sociedade civil no Comitê de Integração da Bacia do Rio Paraíba do Sul - CEIVAP. Tese de doutorado, Universidade Federal da Bahia.

Soares Neto, P. B., Freitas, M., Agra, S. G, (2012) Processo de Gestão das Águas na Bacia Hidrográfica do Lago Guaíba. Anais de evento - I Encontro da Associação Nacional de Pós-graduação e Pesquisa em Ambiente e Sociedade.

Trindade Junior, A. P. (2019). Aperfeiçoamento de ferramentas estaduais de gestão de recursos hídricos no âmbito do Progestão: Considerações sobre um projeto de pesquisa aplicado. Boletim Regional, Urbano e Ambiental, 20, 101-103.

Trindade Junior, A. P. (2020). Relatório de Pesquisa do Projeto de Aperfeiçoamento de ferramentas estaduais de gestão de recursos hídricos no âmbito do Progestão.

Trindade Junior, A. P. Barboza, A. R. M. (2013) A organização, comitê de bacia hidrográfica. Anais do IV Encontro Internacional da Governança da Água.

Trindade Junior, A. P.; Fracalanza, A. P. Federalismo, algumas considerações a partir da gestão de recursos hídricos no Brasil. Anais do $7^{\circ}$ Encontro Nacional da Associação Nacional de Pós-Graduação e Pesquisa em Ambiente e Sociedade. Brasília: 2015.

Wahrlich, B. M. de S. (1974) Reforma administrativa federal brasileira: passado e presente. Revista de Administração Pública, 8, (2), 59-65.

Weber, M., Gerth, H. H., Mills, C. W. (1982). Ensaios de sociologia.

Weber, Max. (1999) Economia e Sociedade: fundamentos da sociologia compreensiva, Brasília: Editora da Universidade de Brasília. (volume 1)

World Bank. (1992) Governance and Development (Relatório).

\section{Notas}

[1]Entrevista realizada em Brasília, no Ministério de Meio Ambiente, no dia 09/12.

[2] Entrevista realizada em Brasília, no Ministério de Meio Ambiente, no dia 09/12.

[3]Entrevista realizada em Resende - RJ, na sede da Agencia Associação Pró-Gestão das Águas da Bacia Hidrográfica do Rio Paraíba do Sul (AGEVAP), no dia 22/03.

[i]De forma sintética, o que se convencionou chamar de "Consenso de Washington" consiste na percepção de conjunto de atores pertencentes às economias centrais, reunidos na Organisation for Economic Co-operation and Development - OECD, que interpretam a crise sul-americana na década de 1980 a partir da premissa de que sua origem residiu no excessivo crescimento do Estado, nas formas do protecionismo, além da regulação demasiada e ineficiente. (Bresser-Pereira, 1991; Portella Filho, 1994; Andrews; Kouzmin, 1998)

[ii]Em função da especificidade do estudo, a terceirização não será abordada.

[iii]Lei Federal no 9.984/2000

[iv]Lei $8.001 / 90$

[v]Evidenciado pelo levantamento de documentos, a saber: editais de convocação e atas.

[vi]A Constituição de 1988 contemplou a administração pública, podendo também ser vista como uma reforma. (Bresser-Pereira, 2011). 